\title{
Analysis of main tasks of precision farming solved with the use of robotic means
}

\author{
Vinh Nguyen ${ }^{1}$, Quyen $\mathrm{Vu}^{1}$, Oksana Solenaya ${ }^{1}$ and Andrey Ronzhin ${ }^{1,2^{*}}$ \\ ${ }^{1}$ SUAI, Department of Electromechanics and Robotics, 190000, Saint-Petersburg, Bolshaya Morskaya Str., 67, Russia \\ ${ }^{2}$ SPIIRAS, Laboratory of Autonomous Robotic Systems, 199178, Saint-Petersburg, 14-th line of V.I., 39, Russia
}

\begin{abstract}
The main classes of problems of exact farming, solved with the involvement of robotics, are discussed. The use of precision navigation systems for robotic agricultural machines allows us to determine the actual soil parameters, calculate the cartograms for fertilizer application, taking into account the spatial variability of the agricultural contour. A promising method is the use of unmanned aerial vehicles for surveying and selecting intra field agricultural contours from a small height. To reduce the variability of soil characteristics in the fields, various robotic means of processing and preparation are used, including for leveling the soil. Given the regularity of planting crops on the fields, automatic systems of parallel driving of agricultural machinery are gaining popularity. Based on the analysis of modern robotic agro systems, promising areas for further research are formulated.
\end{abstract}

\section{Introduction}

The use of new technologies and technical means, such as positioning systems, automatic samplers, sensors, onboard computers, measuring systems and devices, mobile information systems and others, allows one to conduct spot survey of soil characteristics; collect, accumulate and analyze the data; draw up a map of the yield forecast of the cultivated plants; introduce mineral and organic fertilizers, chemical ameliorants in a certain field, taking into account the revealed variability of its characteristics in order to obtain maximum yield, reduce pollution and grow organic products; implement and monitor the intended recommendations; further monitor the characteristics of the field.

Agricultural robots (agrobots) have been discussed for a long time and were initially considered as automatic machines consisting of an executive device in the form of one or several manipulators and a device for controlling their movement [1]. Ten years ago, robots in agriculture were already being developed and existed, carrying out various operations such as: harvesting vegetables and fruits; weeding and thinning of vegetables; processing of greenhouses; commodity preparation of fruit and vegetable and berry products, including sorting, packaging and loading into containers; maintenance of agricultural complexes and livestock, including milking, sanitation, haircut; loading and unloading operations with agricultural products; driving of agricultural machinery, etc.

The active introduction of robotic means and new production technologies in agriculture also contributes to the solution of personnel problems. The scarcity of qualified personnel and young cadres in agriculture in
Russia and other countries has increased even more in recent years. Specialists who choose to work in agriculture are becoming fewer and significant parts of them have pre-retirement age [2]. The prevailing view that agriculture is unattractive for young qualified personnel due to low pay is gradually changing. The use of modern technologies, including the use of robotics, can increase the prestige of the professions of the agrarian sector.

Now the global market for agricultural robots is experiencing significant growth [3-5]. Robots are used in many stages and in various types of agriculture: fieldwork, livestock, production and collection of food [6-8]. The market of agro robots in 2013 reached \$ 817 million and according to expert forecasts it will reach $\$$ 16,3 billion in 2020 [9]. The reasons for this colossal growth are the need for robotization of agricultural production, caused by the following factors: the need to increase labor productivity in agriculture; renewal of equipment and machinery used in agriculture; reduction of personnel risks; the need to facilitate or eliminate workers from physically challenging tasks and others.

For example, milking is one of the most difficult and laborious processes in dairy production, so the problem of automation of milking on farms is being actively explored. In the world market of milking robots, "DeLaval" takes the first place, controlling about 50\% of the market, and is the undisputed leader of the Russian market: DeLaval 56\%, WestphaliaSerge 6\%, Boumatik $5 \%$, Lelly $5 \%$, Impulse AG 4\%. Because of the lack of Russian analogues, the problems of import substitution and increasing the competitiveness of domestic products are relevant in agriculture.

\footnotetext{
"Corresponding author: ronzhin@iiias.spb.su
} 


\section{Analysis of existing agricultural robots}

Examples describing the specific implementation of robots in solving problems of agrarian tasks and precision farming are considered. In work [10], robotics are considered for production and processing of industrial horticultural products, focused on increasing yields, excluding the "human factor" in the production of goods, minimizing the harmful effects of chemicals on humans and the environment. In the All-Russian Institute of Mechanization (AIM) a robotic sprayer has been developed (with a load capacity of $500 \mathrm{~kg}$, dimensions $\mathrm{H}$ x L x W not exceeding 1600 x 2300 x $1800 \mathrm{~mm}$, road clearance $600 \mathrm{~mm}$, the smallest turning radius not more than $299 \mathrm{~mm}$, and speeds of translational motion at work $2-6 \mathrm{~km} / \mathrm{h}$ and for transportation of $8 \mathrm{~km} / \mathrm{h}$ ) with an intelligent control system unit. The chassis of the sprayer uses an electric motor, has sensors and video cameras that provide positioning relative to plants using the technology of spectral image filtration.

At the Ural Agrarian University, the work is underway to create domestic robotics for agriculture, including the development of a set of scientific and methodological documentation regulating the creation, departmental acceptance and operation of agricultural robots; research methods of automation of technological processes in the agro-industrial complex (AIC) with the use of robotics; development of a database on the latest achievements in the field of robotics; carrying out mathematical and semi-detailed modeling of robotic agricultural complexes; creation of executive devices, modules and working bodies; creation of auxiliary systems and sensing systems; creation of prototypes of robots and design documentation for them for serial production [9].

In joint research of the All-Russian Research Institute of Agrochemistry and IPMeh of RAS, the task of robotization of agrochemical services is solved which consists in the creation of automated interactive programs for calculation of fertilizer doses in accordance with electronic agrochemical cartograms of soil fertility, planned crop yields, the level of the previous harvest, moisture availability, relief features, agrophysical soil properties and other factors. For the differentiated application of fertilizers, robotic aggregates consisting of a tractor, a mounted or trailed fertilizer spreader (applicator), electronic equipment including an onboard computer, a GPS/GLONASS navigator, an automatic driving system (autopilot), and additional fertilizing of vegetative crops sensors, are used. According to the results of experimental studies, the yield of cereals was increased from the territorial differentiation of fertilizer doses with the variability of agrochemical indicators of fertility, in various soils with humus content and in different soil-climatic conditions [11].

Also, there are prototypes of foreign robots for processing fruit and berry crops. The strawberry harvesting robot, developed at the California Institute of Technology, performs harvesting of berries by scanning the surface of rows from several sides and analyzing the images. Robotic devices Agrobot SW6010 and AGSHydro of the Spanish company AgroBot are used to collect only mature berries on hydroponic plantations with the help of 60 manipulators and a vision system. The robots of "VisionRoboticsCorporation" and the French company "Wall-ye" are used for trimming vines and equipped with a vision system from several built-in cameras. A full-wheel mobile robot NaioTechnologiesOz of the company Naio Technologies (France) is used for loosening the soil and destroying weeds in the inter-rows of cultivated plants.

In work [12] the possibility of using geostatistical methods for constructing cartograms of spatial distribution of parameter values characterizing soil fertility, as well as yield and quality of wheat grain is analyzed. The parameters under study are divided into three groups: soil characteristics; quantitative indicators of yield; indicators of grain quality. Samples were selected using a rectangular regular grid with a pitch of $25 \times 50 \mathrm{~m}$. The studies performed at the Menkovsky branch of the Agrophysical Research Institute showed that for all the analyzed soil properties there is a fairly strong spatial dependence, and to a greater extent it is related to the position of the sampling points. When choosing a sampling network, it is recommended to take a grid spacing less than half the semi variogram rank and, in a complex study of the field, use a grid with a step of not more than $30 \mathrm{~m}$. The three-component model was based on the geostatistical studies, following which the studied field characteristics were considered as spatial variables, including: large-scale deterministic variation component, spatially correlated medium-scale component, spatially uncorrelated microcomponents. The method of modeling large-scale spatial changes is the construction of a line or surface regression from data obtained by observing at individual points. Characteristics of the soil have a pronounced spatial structure, reflected in the form of agrocontours. A cartogram of soil properties constructed with the help of regression kriging makes it possible to identify areas with an increased or decreased value of agrochemically important properties, and then, depending on the location and size of these zones, to make a decision on differentiated soil cultivation, in particular, to adjust the doses of mineral fertilizers applied. The variability of the characteristics of grain quality and yield in most cases was greater than the variability of soil properties. For yield indicators, there is also a spatial dependence, but weaker than for soil properties. Mapping yields is also possible with regression kriging. Dependences between soil properties and yield indicators can be established by cokriging or factorial kriging to improve accuracy in further research. Characteristics of the quality of wheat grain did not reveal any significant spatial connectivity, so the mapping of spatial distributions of these indicators is limited to the construction of trend surfaces. In this case, one should use any other method of constructing cartograms (for example, by the method of reciprocal distances), or conduct a repeated geostatistical analysis, but using the grid in steps of several meters, which, however, can lead to additional unreasonable costs. 
In work [13] the results of the research of the Precision Agriculture Center of the RGAU-MAAA on the application of navigation equipment for sowing grain crops, differentiated feeding of crops are presented; evaluation of the fertilization of each section of the field with the compilation of electronic yield maps. To accomplish the tasks, the precision seeder D-9-30 was used in the studies with the GPS system and the marker, and the direct seeder DMC-3 using only the autopilot. In the course of the research, the variation in the width of the butt spacing between adjacent passages of seeders during the sowing of grain crops by a marker and autopilot was revealed. The values of the deflection of the butt spacing of the drill D-9-30 on the dumping background when using the marker in the range 3,2-4,8 sm, and when using the autopilot, respectively, was within 1,4-1,8 sm. When sowing cereals on zero and minimal background with the DMC-3 seed drill, the width of the butt-end spacing did not exceed $1 \mathrm{sm}$, averaging $0,1-0,4 \mathrm{sm}$. The quality of sowing was improved. When sowing with a marker, the qualitative characteristics of sowing were lower, the seed consumption increased by an average of $10-15 \%$. To monitor and differentiate the application of fertilizers, depending on the condition of the crop plants, an optical sensor N-Sensor ALS (Germany) was installed on the John Deere tractor to scan the crops. The map of plant development, compiled on the basis of the NDVI-map, allows determining how the biomass is distributed within the field, and to calculate the coordinates of the application of fertilizers. The differentiated application of fertilizers ensured a saving of $15-20 \%$ of mineral fertilizers per hectare. Based on the evaluation of the characteristics of the soil in a particular section of the field, crop yield maps were generated, which allow identifying the problem areas of the field that require the application of fertilizers. The results of the research showed that the yield of cereals depended more on the timely processing and fertilization of the soil than on the technology of its cultivation.

In work [14] a comparative evaluation of parallel driving systems (PDS) for controlling the movement of tractors based on the GPS navigation system was carried out. On the fields of the test range of NTC KubNIITM, a number of PDS were tested, including foreign production: "Geomir-pilot"; RAVEN Cruizer II; EZ guide 250; Topcon X14; S-Lite Outback Guidance; Trimble EZ pilot CFX 750 CenterPoint RTX when carrying out the technological operation of applying solid mineral fertilizers. All of PDS devices were installed on the MTZ-82 tractor in a Bogballe M2 base spreader. The results of the analysis of the performance of the PDS showed the advantage of the Trimble EZ pilot CFX 750 system, which is the most expensive of the systems under consideration. The results of the measurements of the working width of the application of fertilizers indicate that the oscillation of the distance between traces of the tractor's wheels of adjacent passes (expressed in terms of the coefficient of variation) while driving with the PDS ( $\pm 0,075 \mathrm{~m})$ is lower compared to the straightness of driving in the traditional way $( \pm 0,175$ $\mathrm{m})$. On the whole, it was suggested that the scope of work $(4,500 \mathrm{ha})$ for the proposed options for retrofitting a unit of PDS for spreading mineral fertilizers during the cultivation of winter wheat be limited to one MTZ-82 tractor with a Bogballe M2 base mineral fertilizer spreader and one of the analyzed PDS, while in the base variant, two MTZ-82 tractors with Bogballe M2 base spreaders are needed. Thus, the results of implementation of any of the six options for retrofitting the PDS unit in comparison with the base version will result in a $50 \%$ reduction in the demand for tractors and spreaders of mineral fertilizers; decrease in capital investment by 1,18 - 1,36 million rubles. Or by $42,4 \%-$ $28,9 \%$; decrease in the cost of mechanized works by 7,8 - 9,0 rubles per hectare (by $15,7 \%-18,1 \%$ ).

In [15] it is proposed to determine the state of the microrelief of rice checks with the aid of an auto-leveler. The main tasks for the implementation of accurate farming on rice pens: to collect and store the initial data on geodetic survey and soil characteristics of rice checks; create a computer database of the collected data array; manage the process of further collection, accounting and processing of incoming information; to compile current forecasts of rice yields and irrigation water consumption on a check, a map for individual farms, districts and the whole for the coming years; determine the dynamics of deformation of the surface of checks as a function of time and other factors and establish the frequency of planning work; to determine when shooting and store design marks of the layout of rice checks that ensure the balance of excavation; justify the choice of digging and planning machines, planning technologies and technical and economic indicators based on the obtained geodetic and soil characteristics of rice checks. The most relevant geodetic and soil characteristics of precision farming on rice pens are: microrelief of rice checks and its calculated indicators; group and density of soil, determining the difficulty of its development by the working bodies of digging machines; the soil moisture, on which the operating conditions of the machines depend; thickness of the fertile soil layer, establishing the type of planning and technology of planning works.

In the research conducted by OJSC Engineering Center "Luch" for the vertical survey of the surface of the rice check, the AN-2 and AN-3 autoliners installed on the vehicle were used. Vertical survey on the check is carried out from the starting point by rectilinear movement of the vehicle along the marked routes by the shuttle way. To increase the productivity of the autogenerator, it is also planned to use ground-based equipment such as "Agronavigator" (EZ-Guide 250 from Trimble), which works with the satellite navigation system GPS and GLONASS. From the soil-soil characteristics of the rice check, it is recommended first of all to choose the density, soil moisture and the thickness of the fertile soil layer. The density is measured with a densitometer (DORNII drummer), the soil moisture is measured by drying samples or by means of moisture meters by immersion in the ground of special probes with stainless steel sensors, and the thickness of the fertile soil layer is determined by drilling wells or digging holes into the depth of the 
fertile layer in different places of the check. To take samples of soil on the field, the automatic sampler Amity A 2450 (Fritzmeier) is used, which in the laboratory allows determining various soil characteristics, including density, moisture and thickness of the fertile layer. The sampler equipment weighing $100 \mathrm{~kg}$ is mounted on a tractor. The sampling time of one sample is 10-12 seconds, the depth is $61 \mathrm{~cm}$, the number of allowable samples per pass is 25 pieces.

Further increase in productivity and introduction of agro robots is associated with the development of local navigation technologies, precise positioning of manipulators, vision technology, onboard calculators and multisensor sensors, decision support systems based on multi-criteria evaluation, strategies for group management of heterogeneous robots in solving agricultural problems [16-20].

\section{Main tasks of precision farming}

The greatest progress in the robotization of agricultural production is currently visible in the field of precise farming $(\mathrm{PF})$, the distinguishing feature of which is the local differentiation of agrotechnical influences, taking into account the spatial variability of soil and other factors of crop formation within a single agricultural field (agrocontour) [12].

Work in the field of precision farming is divided into 3 main stages: 1) primary exploration, 2) analysis of monitoring results, and 3) development of a field treatment strategy for a specific agricultural operation or in general for the following year. Figure 1 presents a classification of the main tasks of precision farming, solved with the use of robotic agricultural tools, in the three above-mentioned stages.

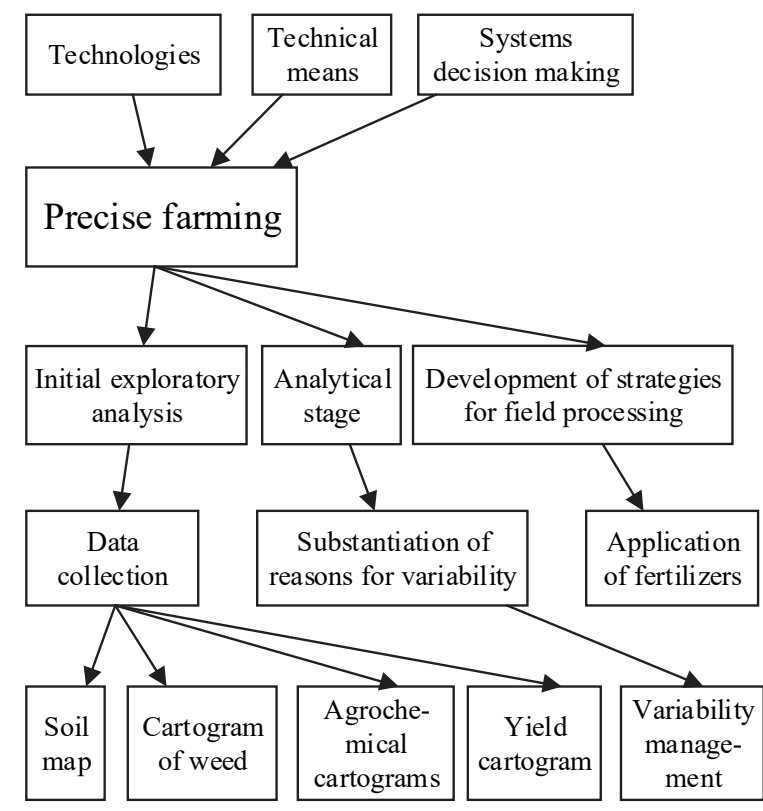

Fig. 1. Classification of the main tasks of precision farming.

The primary exploratory analysis includes the collection of data on conditions on a specific field, as well as various ways to visualize them-drawing up a soil map, plotting cartograms for yields, debris, agrochemical cartograms, and so on. In the studies devoted to precision agriculture, the following classes of problems were solved at the first stage $[12 ; 21]$ : justification of the expediency of differentiating technological impacts; choice of the optimal step and sampling scheme; analysis of the obtained variability of soil properties under different methods of land use, agrotechnology or on different types of fields; the construction of cartograms of agrochemical and agrophysical properties of fields, as well as their yield and contamination [22].

At the analytical stage of $\mathrm{PF}$, the reasons for the variability of soil properties are identified and priority methods for managing them are established. Then, at the third stage, a strategy is developed for processing the field for a specific agricultural operation or in general for the next year. At the same time, the question is solved which fertilizers should be applied, in what doses and how they should be corrected within the considered inhomogeneous field.

Remote sensing based on aerial photography using unmanned aerial vehicles (UAV) in recent years has been actively used due to technical progress, reducing costs and dimensions of sensors, the development of a global positioning system, intelligent programming systems and flight control. Improved parameters of spatial and temporal resolution of aerial photography using UAVs make it possible to extract more data on the state of the leaf cover of the crops. Figure 2 presents a classification of the main monitoring tasks, solved with the help of UAVs on various agricultural lands.

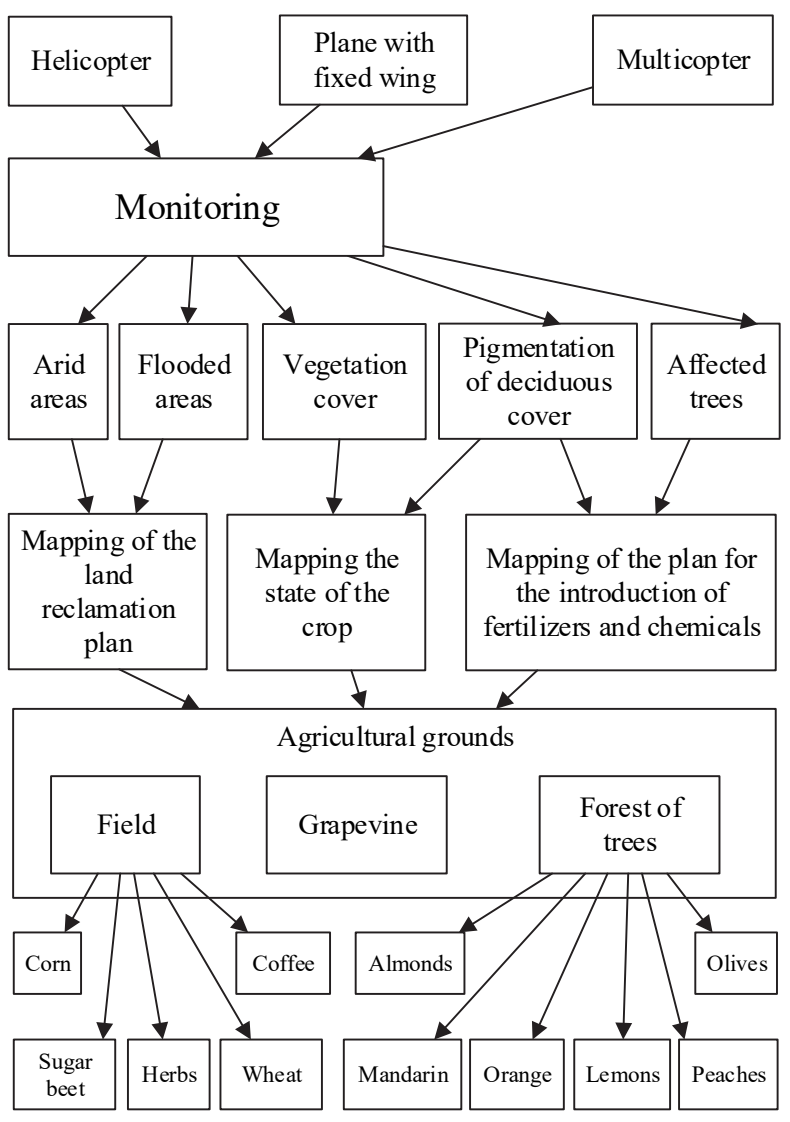

Fig. 2. Classification of tasks of agrarian robotics solved by UAVs. 
The work [11] is devoted to precision agriculture, the problem of analyzing the diversity of in-ground agricultural contours is raised, which is difficult to solve using traditional survey methods and field mapping, calculation of fertilizer doses and their introduction, determination of seed sowing rates, other operations for each allocated agro-contour. Introduction of a part of soils on the field of averaged doses of fertilizers significantly affects the yield and ecological compatibility of the cultivated products.

The development of robotics for precision farming is associated with the solution of a number of problems: the creation of systems for the accurate navigation of agricultural machines; determination of the actual level of soil fertility; calculation of fertilizer doses for the planned yield of agricultural crops.

The task of determining the actual level of fertility in agricultural fields is complicated by the need to isolate the under-floor areas that differ in their fertility. Among the remote methods of analysis are: 1) the use of space vehicles, which is quite expensive, inoperative and the quality of the survey is highly dependent on weather conditions; 2) the use of unmanned aerial vehicles (UAV) for surveying and revealing under-floor agrarian contours from a small height, which is a more promising due to increased accuracy, promptness of the diagnostic survey and relatively low cost. To the terrestrial methods of automatic determination of the yield of agricultural crops, first of all, special on-board sensors installed on harvesters and conducting analysis during harvesting are included.

A promising way of allocating agro-soil contours is topographic survey of field relief. Another way to determine the level of fertility is to scan the electrical conductivity of the soil. These methods, combined with automated sampling of soil and the use of GIStechnologies for the processing of field cartographic material, significantly reduce the costs of agrochemical field survey compared to traditional methods [11].

\section{Conclusion}

The relevance of the application of precision farming in the agrarian sector is caused by the reasons of the transition of traditional agriculture to new production technologies, the solution of personnel problems, increasing productivity and eliminating the human factor from physically challenging tasks. Agricultural robots are used in almost all stages and different types of agriculture. The world market of agricultural robots is developing with significant growth, however, in Russia own production of agricultural robots is still limited.

The use of robotics in precision farming will make it possible to solve a number of problems: the creation of systems for the accurate navigation of agricultural machines; determination of the actual level of soil fertility; calculation of fertilizer doses for the planned yield of agricultural crops. A distinctive feature of accurate farming is the local differentiation of agrotechnical influences, taking into account the spatial variability of soil and other factors of crop formation within the agricultural contour. To the task of determining the actual level of soil fertility, a promising way is to use UAV for surveying and revealing the under-floor agrocontours from a small height. It is connected with the solution of the problem of allocation of agro-soil contours, a topographic method of topography of fields is a promising method.

The analysis of modern works in the field of precision farming has shown that the main achievement of the use of remote and terrestrial methods for monitoring the soil state is the allocation of agrocontours in their fields that differ in their characteristics, and the subsequent processing and application of fertilizers in the agro-contours, depending on their parameters.

To reduce the variability of soil characteristics in the fields, various robotic means of processing and preparation are used, including for leveling the soil. Given the regularity of planting crops on the fields, automatic systems of parallel driving of agricultural machinery are gaining popularity, providing a smaller deviation from straight-ahead driving in comparison with the traditional method. Parallel driving is carried out from the starting point by rectilinear movement of the vehicle along the marked routes by the shuttle way.

This work is partially supported by state research № 00732015-0003 and the Russian Foundation for Basic Research (grant № 16-08-00696).

\section{References}

1. E.I. Yurevich, Fundamentals of robotics (2-nd ed., Revised and additional. - SPb: BHV-Petersburg, 2005)

2. V.I. Nabokov, E.A. Skvortsov, M.K. Saakyan, E.G. Skvortsova, Economic sciences, 4(31), 149-153 (2015)

3. A. Bechar, C. Vigneault, Biosystems Engineering, 149, 94-111 (2016)

4. N. Noguchi, O.C.J. Barawid, Proceedings of the 18th World Congress The International Federation of Automatic Control, 633-637 (2011)

5. S. Wolfert, L. Ge, C. Verdouwa, M.J. Bogaardt, Agricultural Systems, 153, 69-80 (2017)

6. M. Perez-Ru1z, D.C. Slaughter, F.A. Fathallah, C.J. Gliever, B.J. Miller, Biosystems Engineering, 126, 45-55 (2014)

7. F. Rovira-Mas, I. Chatterjee, V. Saiz-Rubio, Computers and Electronics in Agriculture, 112, 172183 (2015)

8. L. Holloway, C. Bear, K. Wilkinson, Journal of Rural Studies, 33, 131-140 (2014)

9. E.A. Skvortsov, Vestnik of the State Agrarian University of the northern Trans-Urals, 3, 113-117 (2015)

10. A.Yu. Izmailov, Z.A. Gojaev, R.A. Afanasiev, Fertility, 5(92), 9-13 (2016) 
11. R.A. Afanasiev, I.L. Ermolov, Mechatronics, automation, management, 12, 828-833 (2016)

12. V.A. Sidorova, E.E. Zhukovsky, P.V. Lekomtsev, V.V. Yakushev, Agrochemistry and fertility of soils, 8, 879-888 (2012)

13. A.I. Belenkov, A.Yu. Tyumakov, M.U. Sabo, Bulletin of the Altai State Agrarian University, 4(126), 5-10 (2015)

14. D.A. Petukhov, M.E. Chaplygin, S.A. Sviridova, V. Voronkov, Agrosnabforum, 1, 18-21 (2016)

15. A.N. Efremov. Collection of proceedings of the conference Integrated melioration - a means of increasing the productivity of agricultural lands, 278-287 (2014).

16. A. Ronzhin, A. Saveliev, O. Basov, S. Solyonyj. Springer-Verlag Berlin Heidelberg, A. Ronzhin et al. (Eds.): ICR 2016, LNCS/LNAI, 9812, 32-39 (2016)

17. N. Pavluk, A. Ivin, V. Budkov, A. Kodyakov, A. Ronzhin. Springer-Verlag Berlin Heidelberg, A. Ronzhin et al. (Eds.): ICR 2016, LNCS/LNAI, 9812, 113-123 (2016)

18. L. Chubraeva, A. Ronzhin, A. Shyshlakov, Al. Ronzhin, V. Shyshlakov. SPIIRAS Proceedings, 33(2), 207-226 (2014)

19. A. Motienko, A. Tarasov, I. Dorozhko, O. Basov. SPIIRAS Proceedings, 46(3), 169-189 (2016)

20. A. Ronzhin, I. Vatamaniuk, N. Pavliuk. 9th International Conference and Exposition on Electrical and Power Engineering (EPE), 675-680 (2016).

21. V.P. Yakushev, E.E. Zhukovsky, V.V. Yakushev Bulletin of the RAACS, 3, 16-20 (2009)

22. P.V. Krasilnikov, V.A. Sidorova. Geostatistics and geography of soils. 67-80 (Moscow: Nauka 2007) 